\title{
Multiple insecticide resistance in Aedes aegypti (Diptera: Culicidae) populations compromises the effectiveness of dengue vector control in French Guiana
}

\author{
Isabelle Dusfour ${ }^{+}$, Véronique Thalmensy, Pascal Gaborit, \\ Jean Issaly, Romuald Carinci, Romain Girod
}

Unité d’Entomologie Médicale, Institut Pasteur de la Guyane, 23 Avenue Pasteur, BP6010 Cayenne cedex 97306, French Guiana

In French Guiana, pyrethroids and organophosphates have been used for many years against Aedes aegypti. We aimed to establish both the resistance level of Ae. aegypti and the ultra low volume spray efficacy to provide mosquito control services with practical information to implement vector control and resistance management. Resistance to deltamethrin and fenitrothion was observed. In addition, the profound loss of efficacy of AquaK'othrine ${ }^{\circledR}$ and the moderate loss of efficacy of Paluthion ${ }^{\circledR} 500$ were recorded. Fenitrothion remained the most effective candidate for spatial application in French Guiana until its removal in December 2010. Further investigation of the mechanism of resistance to deltamethrin demonstrated the involvement of mixed-function oxidases and, to a lesser extent, of carboxylesterases. However, these observations alone cannot explain the level of insecticide resistance we observed during tube and cage tests.

Key words: Aedes aegypti - insecticide resistance - vector control - French Guiana

Dengue fever represents one of the major public health concerns, with millions of cases and thousands of deaths every year in urban, suburban and rural tropical areas (Guzman \& Istúriz 2010). In the Americas, the disease has an endemoepidemic pattern and includes the circulation of all four serotypes. For the past 25 years, outbreaks have occurred every three-five years and their impacts have gradually gained in strength over time, moving towards a hyperendemic situation. Neither specific treatments nor vaccines currently exist against this arbovirosis. Therefore, in addition to specific health care, the most efficient option for fighting the disease is the control of the two vectors, Aedes aegypti and Aedes albopictus. In the 1950s and 60 s, the Pan American Health Organization nearly eradicated Ae. aegypti by targeting adults and immature stages of the organism in domestic habitats with insecticide treatment and breeding site elimination (Gómez-Dantés \& Willoquet 2009). During the 1990s, a new strategy was implemented that was based mainly on large-scale community insecticide spraying. Now, insecticide resistance, especially against pyrethroids and organophosphates, has spread throughout Latin America (Rodríguez et al. 2007). This situation may represent a growing obstacle for dengue vector control programs. To overcome the dengue burden, resistance monitoring, alternative strategies and development of new insecticides or different formulations of current insecticides have been attempted.

Financial support: French Ministry of Health (Department of Health and Social Development, Division of Health and Environment) + Corresponding author: idusfour@pasteur-cayenne.fr

Received 29 November 2010

Accepted 24 February 2011
In French Guiana, which is an overseas French territory, Ae. aegypti is the only dengue vector. Malathion, deltamethrin and temephos have been used for many years for its control. Between 2000-2006, resistance follow-ups across French Guiana demonstrated a strong resistance to temephos (an organophosphate) and the build-up of resistance to deltamethrin (pyrethroid) (Girod et al. 2008). The same studies showed that susceptibility to malathion (organophosphate), fenitrothion (organophosphate) and toxins from Bacillus thuringiensis var israeli (Bti) has remained (Girod et al. 2008). In 2007 and 2008, new evaluations performed in the town of Saint Georges de l'Oyapock (SGO) confirmed the resistance of Ae. aegypti to deltamethrin and demonstrated the recent development of malathion and fenitrothion resistance. Malathion was removed from the market by European Commission (EC) regulations in 2009 (EC 2007, MEEDAT 2008). Currently, Bti has replaced temephos as a larvicidal, while fenitrothion and deltamethrin are sprayed as adulticides. However, the efficacy of sprayed insecticides has not yet been fully evaluated in French Guiana.

The first aim of this study was to determine the resistance level of Ae. aegypti distributed along the coast and to provide mosquito control services with practical information to implement more effective vector control and resistance management strategies in the future. With these goals, the study was conducted from April-June 2009 and was carried out in the lab and in the field to evaluate the performance of deltamethrin and fenitrothion against Ae. aegypti populations. As organophosphates are progressively removed from market by EC regulations, fenitrothion has not been used since December 2010 (EC 2009, MEEDAT 2009). Therefore, to better anticipate the use of pyrethroids, more information on pyrethroid resistance mechanisms was obtained. 


\section{MATERIALS AND METHODS}

Biological material - Five strains of Ae. aegypti were used in this study. Four strains originated from towns in French Guiana: Saint Laurent du Maroni (SLM), Kourou (KOU), Cayenne (CAY) and SGO (Fig. 1). These colonies were established either from field-caught mosquito larvae collected from individual houses (SLM, KOU, CAY) or from eggs laid in ovitraps (SGO). The adults obtained from the F1 progeny were used for bioassays (phase I) and F1 and F2 progeny were used for field experiments (phase II). F1 and F2 CAY strain larvae were used to investigate the potential enzymatic mechanisms involved in insecticide resistance. In addition to natural populations, a susceptible reference PAEA strain, which originated from French Polynesia and has been colonised since 2003 at the Institute Pasteur in French Guiana, was used as a control.

World Health Organization (WHO) filter paper test - Insecticide resistance bioassays were conducted using tarsal contact tests with filter papers treated with technical grades of deltamethrin (CAS \# 52918-63-5) and fenitrothion (CAS \# 122-14-5) (Sigma-Aldrich, St Louis, $\mathrm{MO}, \mathrm{USA}$ ) at the respective diagnostic doses of $0.06 \%$ and $0.5 \%$, as published in Jirakanjanakit et al. (2007). Filter papers were treated according to the WHO protocol (WHO 2005) using acetone solutions of insecticide and silicone oil as the carrier. Impregnation was conducted by evenly dripping $2 \mathrm{~mL}$ of each chemical (technical grade) dissolved in acetone and silicone oil onto the pa-

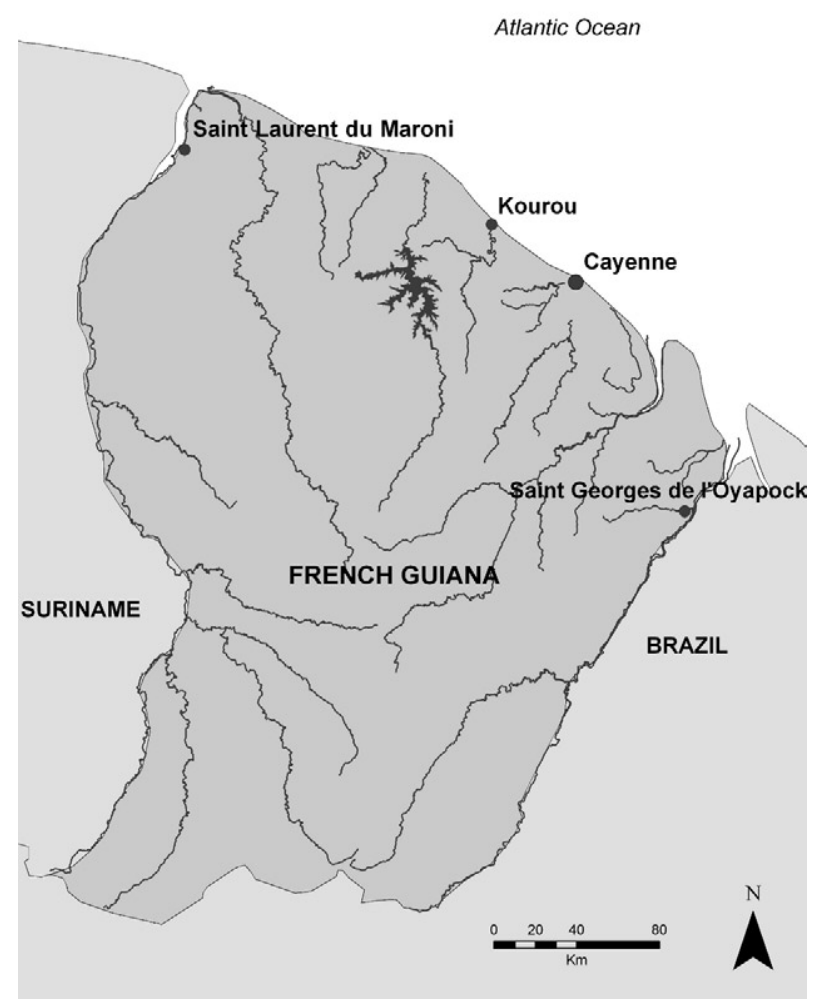

Fig. 1: location of towns in which Aedes aegypti populations were collected in French Guiana. per. The concentrations were expressed in w/v percentage of the active ingredient in silicone oil. The paper was dried for $24 \mathrm{~h}$ before testing. Following the WHO tube test protocol (WHO 2006), four batches of 25 non-bloodfed females (2-5 days old) were introduced into holding tubes for $1 \mathrm{~h}$ and then transferred into the exposure tube and placed vertically for $1 \mathrm{~h}$. Knocked-down and dead mosquitoes were recorded after this time (1 hKD) before being transferred into the holding tubes. A mosquito was recorded as knocked-down if it was lying on its back or side and was unable to maintain flight after a gentle tap. Mortality was recorded $24 \mathrm{~h}$ after exposure (24 hM). Each test was replicated twice $(n=200$ per dose). Controls were performed as mentioned above with a total of two batches of 25 non-blood-fed females (2-5 days old) per replicate $(\mathrm{n}=100$ per dose $)$. The entire experiment was completed at $27 \pm 2^{\circ} \mathrm{C}$ with a relative humidity of 60 $\pm 10 \%$. Ten per cent sugar-soaked cotton was provided to the females during the $24 \mathrm{~h}$ observations.

Ultra low volume (ULV) spray experiments - The two formulations tested were AquaK'othrine ${ }^{\circledR}$ (Bayer, Leverkusen, Germany), in which deltamethrin is the active insecticide, and Paluthion ${ }^{\circledR} 500(500 \mathrm{mg} / \mathrm{L})$, in which fenitrothion is the active compound. The efficacy of these formulations was evaluated by ULV spray against PAEA and the four natural populations of Ae. aegypti strains; the assay was adapted from the WHO cage bioassay method (WHO 2001). The efficacy of each insecticide was evaluated by performing space spray applications using a $4 \times$ 4 vehicle mounted with a fogger. Trials (1 for each formulation) were conducted by the mosquito control services (Service Départemental de Démoustication) late in the afternoon (5:30 pm-7:30 pm) in the town of RemireMontjoly, French Guiana. During application, the speed of the vehicle was $15 \mathrm{~km} / \mathrm{h}$ and the flow rate of the machine was $500 \mathrm{~mL} / \mathrm{min}$. Formulations of AquaK'othrine ${ }^{\circledR}$ and Paluthion ${ }^{\circledR} 500$ were applied at theoretical doses of $1 \mathrm{~g} /$ ha and $250 \mathrm{~g} / \mathrm{ha}$, respectively. Both were prepared according to manufacturer recommendations. Wind speed was recorded with an anemometer (Testo 415, Omniinstruments, Dundee, Scotland, UK).

Collapsible field cages $(30.5 \mathrm{~cm}$ x $30.5 \mathrm{~cm}$ x 30.5 $\mathrm{cm}$ ) (Bioquip products, Rancho Dominguez, CA, USA) covered with a mosquito net (1 $\mathrm{mm}$ mesh) were used to house groups of 50 adult female mosquitoes. The cages were placed on plastic sheets covering the ground for at least $15 \mathrm{~min}$ before the spraying treatments began. Three groups of five cages were placed $20 \mathrm{~m}$ from the path of the vehicle releasing the insecticide and the groups were $5 \mathrm{~m}$ apart. Each cage of the group contained one of the five mosquito strains mentioned above. A typical trial involved 15 cages per insecticide and three cages per mosquito strain $(\mathrm{n}=150)$. The cages were placed downwind and perpendicular to the line of spray. No obstacle was present between the vehicle path and the groups of cages.

In each trial, the knockdown effect was measured by counting the number of knocked-down and dead females $1 \mathrm{~h}$ post-treatment ( $1 \mathrm{hKD})$. All mosquitoes from a particular cage were sucked up into collecting cups $\left(400 \mathrm{~cm}^{3}\right.$ ) (Bioquip products, Rancho Dominguez, CA, USA) and brought back to the laboratory for assessment 
of post-treatment mortality $24 \mathrm{~h}$ later $(24 \mathrm{hM})$. Ten per cent sugar-soaked cotton was provided to the females during the 24-h observation. In each trial and for each strain, one cage containing 50 females was placed as a control in the neighbourhood, out of reach of the insecticide treatment. These cages were also assessed for the knockdown effect $1 \mathrm{~h}$ post-treatment and for mortality $24 \mathrm{~h}$ later and their values were used to correct mortality observed in treatment cages.

Investigating the enzymatic mechanisms of pyrethroid resistance - To assess the level of resistance of the field-caught strains compared to PAEA and to obtain a baseline of mortality for each dose and insecticide, larval bioassays were performed using late third and early fourth instar larvae of the CAY strain. The standard dose-response protocol described by the WHO was followed. For each bioassay, 25 larvae of each strain were transferred to cups containing $99 \mathrm{~mL}$ of distilled water. Four cups per concentration (100 larvae) and five concentrations of acetone-diluted deltamethrin or fenitrothion capable of causing $0-100 \%$ mortality were used. For each concentration, $1 \mathrm{~mL}$ of the insecticide at the desired concentration was added to the cups. Control treatments of $1 \mathrm{~mL}$ of acetone were performed for each test. Larval mortality was recorded $24 \mathrm{~h}$ after exposure.

Following the same protocol, larvae were exposed to the insecticide plus an enzyme inhibitor for $24 \mathrm{~h}$. Three classical detoxification enzyme inhibitors were used: (i) piperonyl butoxide (PBO) (\{5-[2-(2-butoxyethoxy) ethoxy] methyl\}-6-propyl-1,3-benzodioxole - 90\% Fluka, Buchs, Switzerland), an inhibitor of mixed-function oxidases, (ii) S,S,S-tributyl phosphorotrithioate (DEF) $(98 \%$, Chem Service, West Chester, PA, USA), an inhibitor of carboxylesterases and (iii) to a lesser extent, glutathione S-transferases (GSTs) and chlorfenethol (DMC) [1,1-bis (4-chlorophenyl) ethanol; 98\% Pestanal ${ }^{\mathrm{TM}}$, Riedel-deHaën, Seelze, Germany], a specific inhibitor of GSTs. Doses of enzyme inhibitors were determined according to preliminary bioassays that demonstrated the sublethal concentrations of these inhibitors $(0.5 \mathrm{mg} / \mathrm{L}, 0.008 \mathrm{mg} / \mathrm{L}$ and $1 \mathrm{mg} / \mathrm{L}$ for PBO, DEF and DMC, respectively).

Data analysis - The mortality recorded in laboratory bioassays and in the field was corrected for the control mortality by the formula of Abbott (1925) (control mortality ranging from $5-20 \%$ ) such that corrected mortality $=[(\mathrm{X}-\mathrm{Y}) / \mathrm{X}] \times 100$ where $\mathrm{X}=\%$ survival in control cages/cups and $\mathrm{Y}=\%$ survival in treated cages/cups.

The dose-response data obtained from the larval tests were subjected to a Probit analysis (Base SAS software, version 8, 1999, SAS Institute Inc, Cary, NC) to obtain the $\mathrm{LC}_{50}$ and its fiducial limits indicating the theoretical concentration for which $50 \%$ of the larval populations should be dead. The resistance ratio $\left(\mathrm{RR}_{50}\right)$ defined as $\mathrm{LC}_{50}$ (natural population) divided by $\mathrm{LC}_{50}$ (reference strain) was calculated to evaluate the level of resistance of the field-caught population.

The synergistic ratio (SR) and the per cent suppression of deltamethrin tolerance were calculated using $\mathrm{LC}_{50}$ values. The $\mathrm{SR}$ was calculated by dividing the $\mathrm{LC}_{50}$ value of deltamethrin by the $\mathrm{LC}_{50}$ value of deltamethrin plus inhibitor. The per cent suppression was computed as described by Thomas et al. (1991), which is as follows: \% suppression in resistance $=\left[1-\left(\mathrm{LC}_{50}\right.\right.$ of insecticide with synergist/LC ${ }_{50}$ of insecticide without synergist)] $* 100$.

\section{RESULTS}

Tarsal contact with treated filter paper - A total of 200 non-gorged females were exposed from each of the five strains and diagnostic doses. When the mortality in controls $(24 \mathrm{hMC})$ was equal to or higher than $5 \%$, we applied Abbott's formula to the exposed tube results. Deltamethrin caused 27-37\% knocked-down mosquitoes, whereas fenitrothion induced a maximum of $1 \%$ (Table I). Regardless of the insecticide, all PAEA females were dead after the 24-h observation. In deltamethrin-treated tubes, F1 female mortality ranged from $14 \%$ (SLM) to $30 \%$ (SGO) (Table I). Considering the WHO thresholds, all four populations were classified as resistant to deltamethrin. Mortality in fenitrothion-treated tubes was higher than in those treated with deltamethrin, ranging from $22-85 \%$. Therefore, SGO, CAY and KOU populations also exhibited resistance to fenitrothion, while SLM displayed a tolerance with $85 \%$ mortality.

ULV spray experiments - Wind speed did not exceed $15 \mathrm{~km} / \mathrm{h}$ and wind direction was north-south during the two trials. The validity of the experiment was evaluated by the percentage of mortality in controls and the percentage of mortality in the PAEA strain. A mortality of less than $20 \%$ in controls and $99-100 \%$ mortality for PAEA was satisfactory to consider the results valid. A strong knockdown effect was observed after $1 \mathrm{~h}$ for the susceptible PAEA strain, whereas a very minor effect was recorded for the field-caught populations (this ranged from $0-5 \%$ ). As observed with the filter paper test, fenitrothion had low knockdown activity in the natural populations. Mortality results obtained for the natural population strains were also in accordance with the level of resistance observed during the filter paper test (Table II). Indeed, a low efficacy of AquaK'othrine ${ }^{\circledR}$ was recorded across all four populations with mortalities varying from $9-17 \%$. Fenitrothion produced a higher efficacy; mortality of the natural strains varied from $64-91 \%$ (Table II).

Investigating metabolic mechanisms of deltamethrin resistance - Insecticide tests performed on larvae corroborated the resistance status of these organisms at the larval stages: an $\mathrm{RR}_{50}$ of 78 calculated with an $\mathrm{LC}_{50}$ after deltamethrin exposure equalled $7.80 \mu \mathrm{g} / \mathrm{L}$ (6.74-8.97) for the CAY strain and $0.10 \mu \mathrm{g} / \mathrm{L}(0.05-0.24)$ for the PAEA strain. Therefore, we searched for mechanisms potentially involved in this resistance through the exposure to synergists. Based upon the Probit analysis, the $\mathrm{LC}_{50}$ after exposure to deltamethrin plus PBO, DEF or DMC equalled $1.95 \mu \mathrm{g} / \mathrm{L}$ (1.62-2.32), $4.49 \mu \mathrm{g} / \mathrm{L}(3.95-5.04)$ and $18.52 \mu \mathrm{g} / \mathrm{L}$ (14.83-24.07), respectively (Figs 2-4). A moderate implication of mixed-function oxidases and esterases in deltamethrin resistance was suggested by synergist ratios equalling 4.0 and 1.74 , respectively. These results were supported by resistance suppression percentages of $75 \%$ and $42 \%$ for $\mathrm{PBO}$ and DEF, respectively, demonstrating a stronger implication for mixed-function oxidases than for esterases in deltamethrin resistance. No synergist action has been observed using DMC. 
TABLE I

Percentages of $1 \mathrm{~h}$ knocked-down and $24 \mathrm{~h}$ corrected mortality for the five strains exposed to deltamethrin $0.06 \%$ and fenitrothion $0.5 \%$

\begin{tabular}{lcccccc}
\hline Insecticides & $\begin{array}{c}\text { Doses } \\
(\%)\end{array}$ & Strains & $\begin{array}{c}1 \mathrm{hKDC}^{a} \\
(\%)\end{array}$ & $\begin{array}{c}1 \mathrm{hKDT}^{b} \\
(\%)\end{array}$ & $\begin{array}{c}24 \mathrm{hMC}^{c} \\
(\%)\end{array}$ & $\begin{array}{c}24 \mathrm{hMT}^{d} \\
(\%)\end{array}$ \\
\hline Deltamethrin & 0.06 & PAEA & 0 & 100 & 1 & 100 \\
& & CAY & 1 & 34 & 1 & 29 \\
& & KOU & 0 & 31 & 3 & 23 \\
Fenitrothion & SGO & 0 & 37 & 2 & 30 \\
& \multirow{2}{*}{0.5} & SLM & 1 & 27 & 5 & 14 \\
& & PAEA & 0 & 0 & 0 & 100 \\
& & CAY & 0 & 0 & 5 & 41 \\
& & KOU & 0 & 1 & 0 & 48 \\
& & SGO & 0 & 0 & 0 & 22 \\
& & SLM & 0 & 0 & 3 & 85 \\
\hline
\end{tabular}

$a$ : knocked-down in controls after $1 \mathrm{~h} ; b$ : knocked-down in treated tubes after $1 \mathrm{~h} ; c$ : mortality in controls after $24 \mathrm{~h} ; d$ : corrected mortality in treated tubes after 24 h; CAY: Cayenne; KOU: Kourou; PAEA: susceptible reference strain; SGO: Saint Georges de l'Oyapock; SLM: Saint Laurent du Maroni.

TABLE II

Percentages of $1 \mathrm{~h}$ knocked-down and $24 \mathrm{~h}$ corrected mortality for the five strains exposed to AquaK'othrine ${ }^{\circledR}$ and Paluthion $500^{\circledR}$ during ultra low volume operations

\begin{tabular}{|c|c|c|c|c|c|}
\hline Formulations & Strains & $\begin{array}{c}1 \mathrm{hKDC}^{a} \\
(\%)\end{array}$ & $\begin{array}{c}1 \mathrm{hKDT}^{b} \\
(\%)\end{array}$ & $\begin{array}{c}24 \mathrm{hMC}^{c} \\
(\%)\end{array}$ & $\begin{array}{c}24 \mathrm{hMT}^{d} \\
(\%)\end{array}$ \\
\hline \multirow[t]{5}{*}{ AquaK'othrine ${ }^{\circledR}$} & PAEA & 0 & 84 & 4 & 100 \\
\hline & CAY & 0 & 0 & 4 & 9 \\
\hline & $\mathrm{KOU}$ & 0 & 3 & 2 & 11 \\
\hline & SGO & 0 & 1 & 2 & 17 \\
\hline & SLM & 0 & 5 & 6 & 16 \\
\hline \multirow[t]{5}{*}{ Paluthion ${ }^{\circledR} 500$} & PAEA & 0 & 1 & 0 & 99 \\
\hline & CAY & 0 & 0 & 2 & 72 \\
\hline & $\mathrm{KOU}$ & 0 & 0 & 0 & 64 \\
\hline & SGO & 0 & 0 & 0 & 64 \\
\hline & SLM & 0 & 0 & 0 & 91 \\
\hline
\end{tabular}

$a$ : knocked-down in controls after $1 \mathrm{~h} ; b$ : knocked-down in treated cages after $1 \mathrm{~h} ; c$ : mortality in controls after $24 \mathrm{~h} ; d$ : corrected mortality in treated cages after 24 h; CAY: Cayenne; KOU: Kourou; PAEA: susceptible reference strain; SGO: Saint Georges de l'Oyapock; SLM: Saint Laurent du Maroni.

\section{DISCUSSION}

This study establishes a strong resistance to deltamethrin with a poor knockdown effect and low mortality overall for the four populations of Ae. aegypti distributed along the French Guiana coast. In contrast, resistance to fenitrothion was moderate. ULV space sprays used by mosquito control services reflected these resistances with similar mortality results. A highly reduced efficacy of deltamethrin was observed with a poor knockdown effect $1 \mathrm{~h}$ post-treatment, which was associated with a low mortality after $24 \mathrm{~h}$, regardless of the population tested. In addition to their toxicity, pyrethroids are commonly used for their capability to knock down mosquitoes, an effect that induces rapid mosquito elimination in tropical areas. Our results demonstrate the poor efficacy of deltamethrin against Ae. aegypti in French Guiana. However, fenitrothion exhibited a higher efficacy than deltamethrin at $24 \mathrm{~h}$ post-treatment, especially against the populations originating from SLM. Therefore, fenitrothion is the more effective molecule in spatial application in French Guiana. However, this chemical was removed from the EU market in Decem- 
ber 2010. This situation reflects a worldwide problem of increasing insecticide resistance, while the number of chemicals available for public health use is continually reduced. Environmental and toxic issues, difficulties in developing new, efficient compounds and registration constraints are the main causes of the reduced availability of these chemicals. Therefore, it is fundamental to improve the management of resistance in particular by monitoring its level on a regular basis, identifying resistance mechanisms and developing targeting strategies. Multiple insecticide resistance in Ae. aegypti is not an isolated phenomenon; it has already been reported in Latin America (Rodríguez et al. 2002, 2007) and the French West Indies (Marcombe et al. 2009a). Studies from these regions demonstrated that multiple insecticide resistance may be due to the combination the overexpression of genes - such as mixed-function oxidases - involved in metabolic resistance (Flores et al. 2006, Strode et al. 2008, Marcombe et al. 2009b) and target site mutations on the sodium channel gene. Such mutations are extensively described in insects and are known to confer resistance to pyrethroids and DDT called knockdown resistance $(k d r)$. Our results are congruent with these observations. Indeed, the implication in deltamethrin resistance of mixed-function oxidases, and to a lesser extent carboxylesterases, cannot fully explain the level of resistance we observed during the tube and field tests. In 2003, Brengues et al. (2003) found mutations in the Domain II segment 6 of the sodium channel gene in a population from CAY, but no further studies have been conducted. Further investigation of both target site mutations and metabolic resistance of adult organisms must be implemented to better understand the resistance mechanisms involved and their implications for the choice of insecticides in the future.

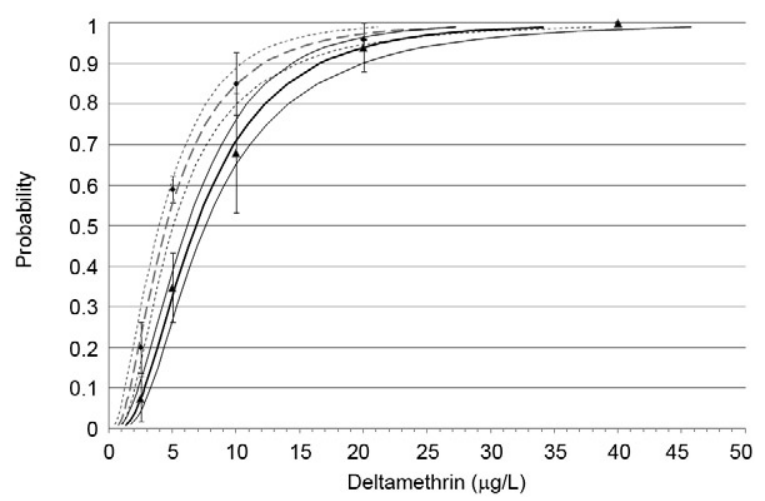

Fig. 2: graph representing dose-response for deltamethrin and deltamethrin plus piperonyl butoxide (PBO) and their estimated data obtained by probit analysis. Mean of observed data and their standard deviations are represented by triangle for deltamethrin and dots for deltamethrin plus PBO. Estimated data curves obtained by probit analysis are represented by a thick dark continuous line for deltamethrin and a thick grey continuous line for deltamethrin plus PBO. Ninety-five per cent fiducial limits are represented by thin dark continuous lines for deltamethrin and thin grey continuous lines for deltamethrin plus PBO.
In addition to a low insecticide efficacy, ULV spray range should be discussed. In our study, the valuation of the ULV space spray was conducted in open areas. However, field conditions could limit the exposure of mosquitoes to insecticides, leading to lower space spray efficacy. This topic is controversial; some studies have proven its efficacy, while others have demonstrated a limited impact on mosquito populations (Arrendondo-Jimenez \& Rivero 2006, Lothrop et al. 2007). Indeed, ULV spraying efficacy depends on a variety of factors (Mount 1998). To

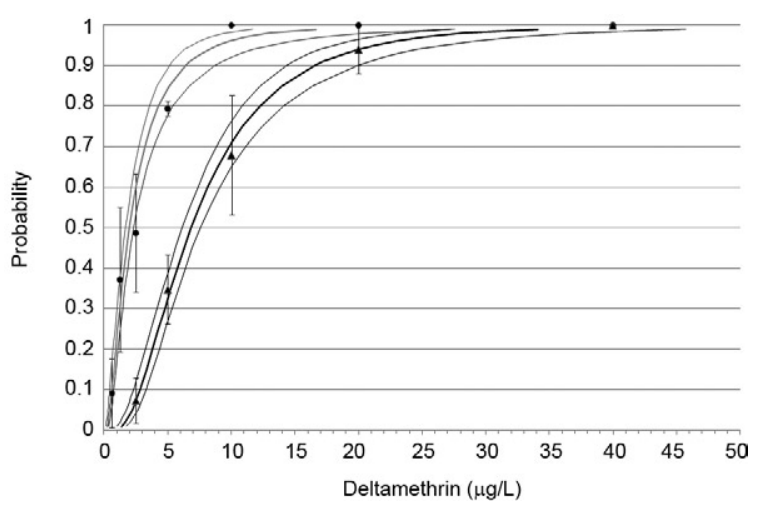

Fig. 3: graph representing dose-response for deltamethrin and deltamethrin plus S,S,S-tributyl phosphorotrithioate (DEF) and their estimated data obtained by probit analysis. Mean of observed data and their standard deviations are represented by triangle for deltamethrin and diamond shapes for deltamethrin plus DEF. Estimated data curves obtained by probit analysis are represented by a thick dark continuous line for deltamethrin and a thick grey dashed line for deltamethrin plus DEF. Ninety-five per cent fiducial limits are represented by thin dark continuous lines for deltamethrin and thin grey dashed lines for deltamethrin plus DEF.

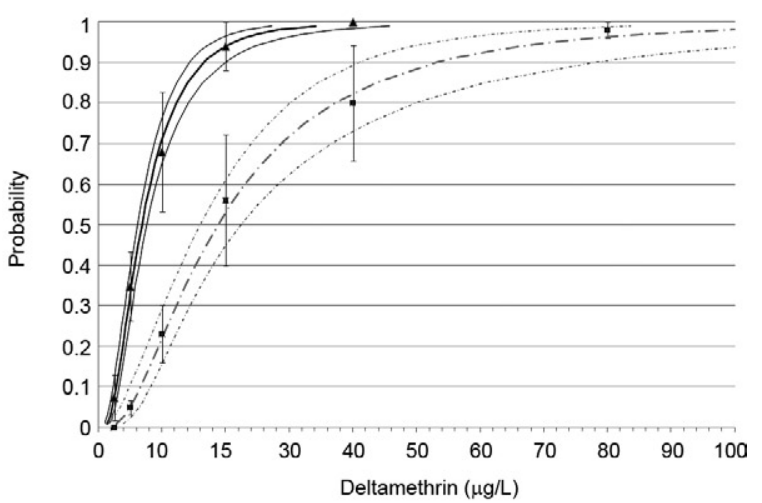

Fig. 4: graph representing dose-response for deltamethrin and deltamethrin plus chlorfenethol (DMC) and their estimated data obtained by probit analysis. Mean of observed data and their standard deviations are represented by triangle for deltamethrin and squares for deltamethrin plus DMC. Estimated data curves obtained by probit analysis are represented by a thick dark continuous line for deltamethrin and a thick grey dashed-and-dottes line for deltamethrin plus DMC. Ninety-five per cent fiducial limits are represented by thin dark continuous lines for deltamethrin and thin grey dashed-and-dotted lines for deltamethrin plus DMC. 
improve the efficacy of insecticide penetration through the environment, different methods of spraying, varied droplet sizes and new insecticide formulations have been tested (Dennett et al. 2006, Hoffmann et al. 2007). However, each configuration seems particular and small-scale field trials should be undertaken to further evaluate the efficacy of the ULV method in French Guiana.

In the absence of efficient vaccines against dengue fever and the increase of insecticide resistance worldwide, high priority must be given to the development of alternative vector control methods. In French Guiana, apart from ULV spraying, biological approaches based on Bti sprays have been implemented and have proven effective, with 100\% mortality against French Guiana Ae. aegypti populations (I Dusfour, unpublished observation). An important part of vector control is educating the public on the elimination of breeding sites to reduce mosquito production. Strengthening such action will be an important initiative but must be employed in concert with other methods to limit Ae. aegypti density. Indeed, when the public is classified according to educational level and knowledge of the disease, it is clear that all people are not involved in these efforts to the same extent (Pérez-Guerra et al. 2009, Shriram et al. 2009). Therefore, control based only on community action may not be easy to achieve. Recent work has successfully identified methods to increase the efficiency of current vector control by using a mixture of larvicides and/or adulticides and/or synergists (Darriet \& Corbel 2006, Lucia et al. 2009), treating at different times during the year (Chung et al. 2001, Lothrop et al. 2008) or using geographic information system technology to optimise spraying operations (Mak et al. 2007). Pull-to-kill strategies (Perich et al. 2003, Williams et al. 2007) also produced promising results by reducing Aedes spp density while targeting them specifically. This advantageous method consists of attracting females to specific, insecticide-containing breeding sites. Research has also been conducted on natural insecticides (Amusan et al. 2005, Chung et al. 2010), entomopathogenic fungi (Scholte et al. 2007, Pelizza et al. 2010) and viruses (Becnel \& White 2007, Lapied et al. 2009) that may provide biological control to replace chemical insecticides. Finally, innovative technologies, such as the sterile insect technique (Benedict \& Robinson 2003) and genetically modified mosquitoes (Wilke et al. 2009), may become tools for the prevention and control of arthropod-borne diseases. However, such techniques are still controversial and the release of such modified insects remains an intensely-debated topic in the scientific world (Alphey et al. 2010).

Based on this study, vector control services in French Guiana were instructed to managing pyrethroid resistance by moderating the use of chemical insecticides. Using Paluthion ${ }^{\circledR} 500$ in a targeted manner until the deadline of authorisation in December 2010 decreased the selective pressure of pyrethroid resistance. After that time, immature stage control using Bti and mechanical removal has been reinforced. Finally, an effort was made to use AquaK'othrine ${ }^{\circledR}$ only during outbreaks. In French Guiana, no other insecticides are yet available to alternate with pyrethroid-based formulations, but the combination of synergists with deltamethrin is being considered for use against adults. In addition, deltamethrin resistance levels are being monitored. Regardless, the implementation of vector control requires a dedicated budget, skilled staff and active community involvement.

\section{ACKNOWLEDGEMENTS}

To the vector control service team of Cayenne, French Guiana, for performing the spatial sprays, particularly to Dr Patrick Rabarison, Mr Léon Lescot, Mr Herman Pagamin and Mr Jean-Paul Alexander.

\section{REFERENCES}

Abbott WS 1925. A method of computing the effectiveness of an insecticide. J Econ Entomol 18: 265-267.

Alphey L, Benedict M, Bellini R, Clark GG, Dame DA, Service MW, Dobson SL 2010. Sterile-insect methods for control of mosquitoborne diseases: an analysis. Vector Borne Zoonotic Dis 10: 295-311.

Amusan AA, Idowu AB, Arowolo FS 2005. Comparative toxicity effect of bush tea leaves (Hyptis suaveolens) and orange peel (Citrus sinensis) oil extract on larvae of the yellow fever mosquito Aedes aegypti. Tanzan Health Res Bull 7: 174-178.

Arrendondo-Jimenez JI, Rivero NE 2006. Space treatments of insecticide for control of dengue virus vector Aedes aegypti in southern Mexico. I. Baseline penetration trials in open field and houses. J Am Mosq Control Assoc 22: 301-305.

Becnel JJ, White SE 2007. Mosquito pathogenic viruses - the last 20 years. J Am Mosq Control Assoc 23 (Suppl. 2): 36-49.

Benedict MQ, Robinson AS 2003. The first releases of transgenic mosquitoes: an argument for the sterile insect technique. Trends Parasitol 19: 349-355.

Brengues C, Hawkes NJ, Chandre F, McCarroll L, Duchon S, Guillet P, Manguin S, Morgan JC, Hemingway J 2003. Pyrethroid and DDT cross-resistance in Aedes aegypti is correlated with novel mutations in the voltage-gated sodium channel gene. Med Vet Entomol 17: 87-94.

Chung IM, Seo SH, Kang EY, Park WH, Moon HI 2010. Larvicidal effects of the major essential oil of Pittosporum tobira against Aedes aegypti (L.). J Enzyme Inhib Med Chem 25: 391-393.

Chung YK, Lam-Phua SG, Chua YT, Yatiman R 2001. Evaluation of biological and chemical insecticide mixture against Aedes aegypti larvae and adults by thermal fogging in Singapore. Med Vet Entomol 15: 321-327.

Darriet F, Corbel V 2006. Laboratory evaluation of pyriproxyfen and spinosad, alone and in combination, against Aedes aegypti larvae. J Med Entomol 43: 1190-1194.

Dennett JA, Stark PM, Vessey NY, Parsons RE, Bueno R Jr 2006. Estimation of aerosol droplet sizes by using a modified DC-III portable droplet measurement system under laboratory and field conditions. J Am Mosq Control Assoc 22: 707-717.

EC - European Commission 2007. Commission decision of 14 August 2007 concerning the non-inclusion in Annex I, IA, IB to directive 98/8/EC of the European Parliament and of the Council concerning the placing of biocidal products on the market of certain substances to be examined under the 10-year work programme refered to in Article 16(2) thereof. European Commission 2007/525/ EC. Available from: www.salute.gov.it/imgs/C_17_pagineBiocidi_30_listaFile_itemName_14_file.pdf.

EC - European Commission 2009. Commission decision of 14 April 2009 concerning the non-inclusion of certain substances in annex I, IA, IB to directive 98/8/EC of the European Parliament and of 
the Council concerning the placing of biocidal products on the market. European Commission, 2009/324/EC. Available from: www.salute.gov.it/imgs/C_17_pagineBiocidi_30_listaFile_itemName_0_file.pdf.

Flores AE, Grajales JS, Salas IF, Garcia GP, Becerra MH, Lozano S, Brogdon WG, Black WC 4th, Beaty B 2006. Mechanisms of insecticide resistance in field populations of Aedes aegypti (L.) from Quintana Roo, Southern Mexico. J Am Mosq Control Assoc 22: 672-677.

Girod R, Gaborit P, Carinci R, Issaly J 2008. Sensibilité d'Aedes aegypti aux insecticides utilisés pour la lutte antivectorielle en Guyane. BASAG 5: 3-4.

Gómez-Dantés H, Willoquet JR 2009. Dengue in the Americas: challenges for prevention and control. Cad Saude Publica 25 (Suppl. 1): S19-31.

Guzman A, Istúriz RE 2010. Update on the global spread of dengue. Int J Antimicrob Agents 36 (Suppl. 1): S40-42.

Hoffmann WC, Walker TW, Smith VL, Martin DE, Fritz BK 2007. Droplet-size characterization of handheld atomization equipment typically used in vector control. J Am Mosq Control Assoc 23: 315-320.

Jirakanjanakit N, Rongnoparut P, Saengtharatip S, Chareonviriyaphap T, Duchon S, Bellec C, Yoksan S 2007. Insecticide susceptible/resistance status in Aedes (Stegomyia) aegypti and Aedes (Stegomyia) albopictus (Diptera: Culicidae) in Thailand during 2003-2005. J Econ Entomol 100: 545-550.

Lapied B, Pennetier C, Apaire-Marchais V, Licznar P, Corbel V 2009. Innovative applications for insect viruses: towards insecticide sensitization. Trends Biotechnol 27: 190-198.

Lothrop H, Lothrop B, Palmer M, Wheeler S, Gutierrez A, Gomsi D, Reisen WK 2007. Evaluation of pyrethrin and permethrin ground ultra-low volume applications for adult Culex control in rural and urban environments of the Coachella Valley of California. $J \mathrm{Am}$ Mosq Control Assoc 23: 190-207.

Lothrop HD, Lothrop BB, Gomsi DE, Reisen WK 2008. Intensive early season adulticide applications decrease arbovirus transmission throughout the Coachella Valley, Riverside County, California. Vector Borne Zoonotic Dis 8: 475-489.

Lucia A, Harburguer L, Licastro S, Zerba E, Masuh H 2009. Efficacy of a new combined larvicidal-adulticidal ultralow volume formulation against Aedes aegypti (Diptera: Culicidae), vector of dengue. Parasitol Res 104: 1101-1107.

Mak S, Buller M, Furnell A, MacDougall L, Henry B 2007. Use of geographic information systems to assess the feasibility of groundand aerial-based adulticiding for West Nile virus control in British Columbia, Canada. J Am Mosq Control Assoc 23: 396-404.

Marcombe S, Carron A, Darriet F, Etienne M, Agnew P, Tolosa M, YpTcha MM, Lagneau C, Yébakima A, Corbel V 2009a. Reduced efficacy of pyrethroid space sprays for dengue control in an area of Martinique with pyrethroid resistance. Am J Trop Med Hyg 80: 745-751.

Marcombe S, Poupardin R, Darriet F, Reynaud S, Bonnet J, Strode C, Brengues C, Yébakima A, Ranson H, Corbel V, David JP 2009b. Exploring the molecular basis of insecticide resistance in the dengue vector Aedes aegypti: a case study in Martinique Island (French West Indies). BMC Genomics 10: 494.

MEEDAT - Ministère de L'écologie, de L'énergie, du Développement Durable et de L'aménagement du Territoire 2008. Arrêté du 21 août 2008 concernant l'interdiction d'utilisation de certains produits biocides. Version consolidée au 27 août 2008. DEVP0820250A. Available from: www.legifrance.gouv.fr/affichTexte.do?cidTexte =JORFTEXT000019375714.

MEEDAT - Ministère de L'écologie, de L'énergie, du Développement Durable et de L'aménagement du Territoire 2009. Arrêté du 9 septembre 2009 concernant l'interdiction d'utilisation de certains produits biocides. Version consolidée au 23 septembre 2009. Ministère de l'écologie de l'énergie du développement durable et de la mer en charge des technologies vertes et des négociations sur le climat, DEVP0920597A. Available from: www.legifrance. gouv.fr/affichTexte.do?cidTexte=JORFTEXT000021059748\&dat eTexte $=\&$ categorieLien $=$ id.

Mount GA 1998. A critical review of ultralow-volume aerosols of insecticide applied with vehicle-mounted generators for adult mosquito control. J Am Mosq Control Assoc 14: 305-334.

Pelizza SA, Scorsetti AC, Lastra CC, García JJ 2010. Production of oogonia and oospores of Leptolegnia chapmanii Seymour (Straminipila: Peronosporomycetes) in Aedes aegypti (L.) larvae at different temperatures. Mycopathologia 169: 71-74.

Pérez-Guerra CL, Zielinski-Gutierrez E, Vargas-Torres D, Clark GG 2009. Community beliefs and practices about dengue in Puerto Rico. Rev Panam Salud Publica 25: 218-226.

Perich MJ, Kardec A, Braga IA, Portal IF, Burge R, Zeichner BC, Brogdon WA, Wirtz RA 2003. Field evaluation of a lethal ovitrap against dengue vectors in Brazil. Med Vet Entomol 17: 205-210.

Rodríguez MM, Bisset J, Ruiz M, Soca A 2002. Cross-resistance to pyrethroid and organophosphorus insecticides induced by selection with temephos in Aedes aegypti (Diptera: Culicidae) from Cuba. J Med Entomol 39: 882-888.

Rodríguez MM, Bisset JA, Fernández D 2007. Levels of insecticide resistance and resistance mechanisms in Aedes aegypti from some Latin American countries. J Am Mosq Control Assoc 23: 420-429.

Scholte EJ, Takken W, Knols BG 2007. Infection of adult Aedes aegypti and Ae. albopictus mosquitoes with the entomopathogenic fungus Metarhizium anisopliae. Acta Trop 102: 151-158.

Shriram AN, Sugunan AP, Manimunda SP, Vijayachari P 2009. Community-centred approach for the control of Aedes spp. in a periurban zone in the Andaman and Nicobar Islands using temephos. Natl Med J India 22: 116-120.

Strode C, Wondji CS, David JP, Hawkes NJ, Lumjuan N, Nelson DR, Drane DR, Karunaratne SH, Hemingway J, Black WC 4th, Ranson $\mathrm{H} 2008$. Genomic analysis of detoxification genes in the mosquito Aedes aegypti. Insect Biochem Mol Biol 38: 113-123.

Thomas A, Kumar S, Pillai MKK 1991. Piperonyl butoxide as a countermeasure for deltamethrin-resistance in Culex quinquefasciatus Say. Entomon 16: 1-10.

WHO - World Health Organization 2001. Guidelines for assessing the efficacy of insecticidal space sprays for control of the dengue vector Aedes aegypti. WHO/CDS/CPE/PVC/2001.1. Available from: whqlibdoc.who.int/hq/2001/WHO_CDS_CPE_PVC_2001.1.pdf.

WHO - World Health Organization 2005. Guidelines for laboratory and field testing of long-lasting insecticidal mosquito nets. WHO/ CDS/WHOPES/GCDPP/2005.11. Available from: whqlibdoc. who.int/hq/2005/WHO_CDS_WHOPES_GCDPP_2005.11.pdf.

WHO - World Health Organization 2006. Guidelines for testing mosquito adulticides for indoor residual spraying and treatment of mosquito nets. WHO/CDS/WHOPES/NTD/2006.3. Available from: whqlibdoc.who.int/hq/2006/WHO_CDS_NTD_WHOPES_ GCDPP_2006.3_eng.pdf.

Wilke AB, Gomes A de C, Natal D, Marrelli MT 2009. Control of vector populations using genetically modified mosquitoes. Rev Saude Publica 43: 869-874.

Williams CR, Ritchie SA, Long SA, Dennison N, Russell RC 2007. Impact of a bifenthrin-treated lethal ovitrap on Aedes aegypti oviposition and mortality in north Queensland, Australia. J Med Entomol 44: 256-262. 